\title{
Attenuation of post-infarction remodeling in rats by sustained myocardial growth hormone administration
}

Citation for published version (APA):

Daskalopoulos, E. P., Vilaeti, A. D., Barka, E., Mantzouratou, P., Kouroupis, D., Kontonika, M., Tourmousoglou, C., Papalois, A., Pantos, C., Blankesteijn, W. M., Agathopoulos, S., \& Kolettis, T. M. (2015). Attenuation of post-infarction remodeling in rats by sustained myocardial growth hormone administration. Growth Factors, 33(4), 250-258. https://doi.org/10.3109/08977194.2015.1072527

Document status and date:

Published: 01/01/2015

DOI:

10.3109/08977194.2015.1072527

Document Version:

Publisher's PDF, also known as Version of record

Document license:

Taverne

Please check the document version of this publication:

- A submitted manuscript is the version of the article upon submission and before peer-review. There can be important differences between the submitted version and the official published version of record.

People interested in the research are advised to contact the author for the final version of the publication, or visit the DOI to the publisher's website.

- The final author version and the galley proof are versions of the publication after peer review.

- The final published version features the final layout of the paper including the volume, issue and page numbers.

Link to publication

\footnotetext{
General rights rights.

- You may freely distribute the URL identifying the publication in the public portal. please follow below link for the End User Agreement:

www.umlib.nl/taverne-license

Take down policy

If you believe that this document breaches copyright please contact us at:

repository@maastrichtuniversity.nl

providing details and we will investigate your claim.
}

Copyright and moral rights for the publications made accessible in the public portal are retained by the authors and/or other copyright owners and it is a condition of accessing publications that users recognise and abide by the legal requirements associated with these

- Users may download and print one copy of any publication from the public portal for the purpose of private study or research.

- You may not further distribute the material or use it for any profit-making activity or commercial gain

If the publication is distributed under the terms of Article $25 \mathrm{fa}$ of the Dutch Copyright Act, indicated by the "Taverne" license above, 


\section{Attenuation of post-infarction remodeling in rats by sustained myocardial growth hormone administration}

Evangelos P. Daskalopoulos, Agapi D. Vilaeti, Eleonora Barka, Polixeni Mantzouratou, Dimitrios Kouroupis, Marianthi Kontonika, Christos Tourmousoglou, Apostolos Papalois, Constantinos Pantos, W. Matthijs Blankesteijn, Simeon Agathopoulos \& Theofilos M. Kolettis

To cite this article: Evangelos P. Daskalopoulos, Agapi D. Vilaeti, Eleonora Barka, Polixeni Mantzouratou, Dimitrios Kouroupis, Marianthi Kontonika, Christos Tourmousoglou, Apostolos Papalois, Constantinos Pantos, W. Matthijs Blankesteijn, Simeon Agathopoulos \& Theofilos M. Kolettis (2015) Attenuation of post-infarction remodeling in rats by sustained myocardial growth hormone administration, Growth Factors, 33:4, 250-258, DOI: 10.3109/08977194.2015.1072527

To link to this article: https://doi.org/10.3109/08977194.2015.1072527

Published online: 12 Aug 2015.

Џ Article views: 166

View Crossmark data
Submit your article to this journal 주 


\title{
Attenuation of post-infarction remodeling in rats by sustained myocardial growth hormone administration
}

\author{
Evangelos P. Daskalopoulos ${ }^{1,2} *$, Agapi D. Vilaeti ${ }^{2}$, Eleonora Barka ${ }^{2,3} *$, Polixeni Mantzouratou ${ }^{4}$, Dimitrios \\ Kouroupis ${ }^{5}$, Marianthi Kontonika ${ }^{2}$, Christos Tourmousoglou ${ }^{2}$, Apostolos Papalois ${ }^{2,6}$, Constantinos Pantos ${ }^{4}$, \\ W. Matthijs Blankesteijn ${ }^{1}$, Simeon Agathopoulos ${ }^{3}$, and Theofilos M. Kolettis ${ }^{2}$
}

\begin{abstract}
${ }^{1}$ Department of Pharmacology, Cardiovascular Research Institute Maastricht, Maastricht University, Maastricht, The Netherlands, ${ }^{2}$ Cardiovascular Research Institute, loannina, Athens, Greece, ${ }^{3}$ Ceramics and Composites Laboratory, Department of Materials Science and Engineering, University of loannina, loannina, Greece, ${ }^{4}$ Department of Pharmacology, Medical School, University of Athens, Athens, Greece, ${ }^{5}$ Department of Biomedical Research, Foundation for Research and Technology-Hellas, Institute of Molecular Biology and Biotechnology, loannina, Greece, and ${ }^{6}$ Experimental Research Center ELPEN, Pikermi, Athens, Greece
\end{abstract}

\begin{abstract}
Prevention of left ventricular remodeling is an important therapeutic target post-myocardial infarction. Experimentally, treatment with growth hormone $(\mathrm{GH})$ is beneficial, but sustained local administration has not been thoroughly investigated. We studied 58 rats $(322 \pm 4 \mathrm{~g})$. GH was administered via a biomaterial-scaffold, following in vitro and in vivo evaluation of degradation and drug-release curves. Treatment consisted of intra-myocardial injection of saline or alginate-hydrogel, with or without $\mathrm{GH}, 10 \mathrm{~min}$ after permanent coronary artery ligation. Echocardiographic and histologic remodeling-indices were examined 3 weeks postligation, followed by immunohistochemical evaluation of angiogenesis, collagen, macrophages and myofibroblasts. GH-release completed at 3 days and alginate-degradation at $\sim 7$ days Alginate $+\mathrm{GH}$ consistently improved left ventricular end-diastolic and end-systolic diameters, ventricular sphericity, wall tension index and infarct-thickness. Microvascular-density and myofibroblast-count in the infarct and peri-infarct areas were higher after alginate $+\mathrm{GH}$. Macrophage-count and collagen-content did not differ between groups. Early, sustained $\mathrm{GH}$-administration enhances angiogenesis and myofibroblast-activation and ameliorates post-infarction remodeling.
\end{abstract}

\section{Keywords \\ Alginate, angiogenesis, growth hormone, myofibroblasts, myocardial infarction, ventricular remodeling}

\section{History}

Received 18 April 2015

Revised 18 June 2015

Accepted 10 July 2015

Published online 12 August 2015

\section{Introduction}

Myocardial infarction (MI) is a common clinical entity, associated with substantial morbidity and mortality. Despite reperfusion that salvages contractile tissue, extensive myocardial necrosis results in left ventricular (LV) remodeling and dysfunction, with ultimate transition to chronic heart failure (Sutton \& Sharpe, 2000). Triggered by elevated wallstress, this process initiates shortly after acute coronary occlusion, leading to infarct thinning and expansion, with subsequent dilatation of the non-infarcted zones (Agathopoulos $\&$ Kolettis, 2014). As these changes occur mostly during the early post-MI period (Ertl \& Frantz, 2005), interventions targeting infarct expansion may prevent subsequent global alterations in LV architecture and function (Mitsi et al., 2005).

Several lines of evidence implicate the growth hormone/ insulin-like growth factor-1 (GH/IGF-1) axis as an important

\footnotetext{
*These authors equally contributed to this study.

Correspondence: Theofilos M. Kolettis, Professor in Cardiology, University of Ioannina, 1 Stavrou Niarxou Avenue, 45110 Ioannina, Greece. Tel: +30 (265)1007227. Fax: +30 (265)1007053. E-mail: theofilos.m.kolettis@gmail.com
}

regulator of post-MI remodeling (Friberg et al., 2000). Accordingly, experimental studies have shown attenuated LV dilatation, improved LV function and lower mortality after systemic GH-administration post-MI (Cittadini et al., 1997, 2003; Jin et al., 2002; Omerovic et al., 2000). Local delivery in the infarct-zone has been advocated by our group (Hatzistergos et al., 2008) and others (Jayasankar et al., 2004), because it maximizes efficacy and avoids systemic effects; for example, acute intra-coronary administration of GH (Mitsi et al., 2006) or IGF-1 (O'Sullivan et al., 2011) in the porcine MI-model produced long-term beneficial effects on LV architecture and function. However, it is unknown whether this action can be potentiated, if treatment is sustained during the critical early post-MI period.

During the past decade, biomaterials have been extensively evaluated in cardiac-repair strategies, based on their chemical and physical properties that permit their use as tissueengineering constructs; moreover, biomaterials can be viewed as ideal candidates for controlled and sustained local delivery of various agents, thereby prolonging their therapeutic actions (Kolettis et al., 2011). Based on this concept, we hypothesized that, local myocardial GH-administration via a biodegradable 
scaffold may enhance the effects of each individual approach and may prevent adverse LV alterations, if initiated immediately post-MI. We opted to use alginate, a naturally occurring, water-soluble polysaccharide co-polymer with gel-forming features, that meets most requirements for cardiac tissueengineering (Augst et al., 2006). Alginate can be fabricated in liquid form in vitro, enabling the addition of proteins, but after intra-myocardial injection in vivo, it cross-links with calcium ions and undergoes transition into a viscous scaffold (Rowley et al., 1999). Due to these properties, alginate exerts favorable effects on LV remodeling in the rat (Landa et al., 2008) and porcine (Mukherjee et al., 2008) MI-models. Furthermore, such treatment appears safe, in terms of acutephase arrhythmogenesis and short-term mortality (Kontonika et al., 2014).

In this study, we examined the value of sustained, local GH-release via an alginate-hydrogel on post-MI LV remodeling in the rat-model. Enhanced myocardial contractility and decreased apoptosis mediate the benefits of GH-treatment in the post-MI setting (Cittadini et al., 1997; Cittadini et al., 2003), but additional mechanisms are likely (Khan et al., 2001). Thus, based on previous evidence (Cook et al., 1988; Lee et al., 2010; Struman et al., 1999), we aimed to shed further light into myofibroblast-activation and angiogenesis.

\section{Methods}

\section{Fabrication of biomaterials}

Alginate-hydrogel was prepared by dissolving alginic-acid sodium-salt (180947, Sigma Aldrich, St. Louis, MO) in normal-saline, using magnetic stirring and ultrasonic agitation (solution A). A second solution (solution B) was prepared by dissolving $\mathrm{D}$-(+)-gluconic acid $\delta$-lactone ([GDL], G2164, Sigma Aldrich) and dehydrated $\mathrm{CaCl}_{2}$ (21074, Fluka Analytical, Sigma Aldrich) in normal-saline. An equal volume $(200 \mu \mathrm{l})$ of solution B was added drop-wise into solution $\mathrm{A}$, under continuous stirring with a micropipette, allowing chelation of calcium ions with $\alpha$-L-guluronic acid residues; this method controls cross-linking and results in a well-developed network (Augst et al., 2006). For alginate + GH, GH (S8648, Sigma Aldrich) was dissolved in normal-saline and was added dropwise into solution A, under constant magnetic stirring for $30 \mathrm{~min}$, followed by the addition of solution B. The final alginate-hydrogel (concentrations: alginic acid $1 \%$ per weight; $\mathrm{CaCl}_{2} 4.2 \mathrm{mM}$; GDL $8.4 \mathrm{mM}$ ) was stored in $0.2 \mathrm{ml}$-aliquots; based on our previous work (Elaiopoulos et al., 2007; Hatzistergos et al., 2008), each alginate $+\mathrm{GH}$ aliquot contained $5 \mu \mathrm{g}$ of $\mathrm{GH}$.

\section{In vitro degradation of alginate}

In vitro degradation was determined on $5 \mathrm{ml}$ alginate-hydrogel, laid gently on the bottom of a beaker. After adding $4 \mathrm{ml}$ double-distilled water over its layer, the beaker was placed in an incubator at $37^{\circ} \mathrm{C} ; 3 \mathrm{ml}$ of the supernatant liquid was sampled at 1, 3, 6, 12 and $24 \mathrm{~h}$, and daily thereafter for a total of 8 days. The spectra were recorded with a UV-visible photometer (UV-Vis mini 1240, Spectrophotometer,
Shimadzu, Kyoto, Japan), and the absorption bands between 240 and $300 \mathrm{~nm}$, characteristic of the alginate components (Nagasawa et al., 2000), were recorded. The concentration of alginate in the samples was calculated after fitting a calibration-curve from maximal absorption values.

\section{GH-release rate measurements}

GH-release from the alginate-hydrogel was examined with fluorescence spectroscopy (RF-5301 PC, Spectrophotometer, Shimadzu), which enables precise measurements at nanoscale. The specific assay lies on the intrinsic fluorescence probes of tyrosine and tryptophan residues in $\mathrm{GH}$, based on their sensitivity to electronic environment. We recorded spectra at emission wavelength of $329 \mathrm{~nm}$ and excitation wavelength of $280 \mathrm{~nm}$, with the calibration-curve fitted using distilled water and aqueous solutions of $\mathrm{GH}$ (at various concentrations). Subsequently, alginate-hydrogel samples with or without $\mathrm{GH}$ were examined at $1,3,6,12$ and $24 \mathrm{~h}$, and daily thereafter for a total of 4 days.

\section{Experimental animal-population and ethics}

The in vivo part of the study was conducted on 58 Wistar rats (all male, 16-18 weeks of age, weighing $322 \pm 4 \mathrm{~g}$ ). Of these, 52 rats were subjected to MI, whereas six rats were sham-operated. The animals received humane care, according to the guiding principles of the Declaration of Helsinki (regarding ethical conduct of animal-research) and to European legislation (European Union directive for the protection of animals used for scientific purposes 2010/63/ EU). They were housed in plexiglas-cages in groups of two, under optimal laboratory conditions regarding temperature $\left(20-22^{\circ} \mathrm{C}\right)$, humidity $(\sim 70 \%)$ and light:dark cycles (12:12); water and standard rodent pellet-diet were provided ad libitum. The study protocol was approved by the institutional review board and by the responsible regulatory state authorities.

\section{In vivo degradation of alginate}

Biotin was incorporated in alginate by carbodiimide-chemistry; specifically, biotin-hydrazide was added to the alginatesolution in 0.1 M MES buffer, at $\mathrm{pH} 6.0$, under stirring for $60 \mathrm{~min}$ at room temperature. The resultant polymer was dialyzed against double-deionized water using a 10,000MWCO-membrane; the water was changed twice daily for 3 days, followed by dropwise addition of $2.9 \mathrm{mM} \mathrm{CaCl}_{2}$. The biotin-alginate scaffold was characterized in vitro by FTIR spectroscopy.

The scaffold was implanted $10 \mathrm{~min}$ after MI-induction (see below) in a separate group of 10 rats $(302 \pm 6 \mathrm{~g})$, which were compared with intra-myocardial injections of normal-saline $(n=6,310 \pm 5 \mathrm{~g})$. The animals were sacrificed (as described below), three ( $n=3$ alginate, $n=2$ saline), seven $(n=4$ alginate, $n=2$ saline) and $15(n=3$ alginate, $n=2$ saline $)$ days after implantation. Biotin-labeled alginate was examined in $5 \mu \mathrm{m}$-sections, immunostained with streptavidin-HRP; the sections were photographed, and the areas of avidin-biotin positive staining were measured with ImageJ software (NIH, Bethesda, MD). 


\section{Animal groups}

The treatment-effects on LV remodeling were examined in 42 rats $(330 \pm 5 \mathrm{~g})$, randomly forming the following groups: (A) sham-operated animals, in which no MI was induced and no treatment was administered $(n=6)$, (B) control (MIinduction, followed by normal-saline intra-myocardial injections, $n=12$ ), (C) alginate-gel intra-myocardial injections post-MI (alginate, $n=12$ ); (D) intra-myocardial injections of alginate-gel containing $\mathrm{GH}$ post-MI (alginate $+\mathrm{GH}, n=12$ ).

\section{In vivo experimental protocol}

The animal body-weight was recorded at the beginning and at the end of the in vivo experiments. Treatment was administered $10 \mathrm{~min}$ after MI-induction; following echocardiographic assessment of LV remodeling three weeks post-MI, the rats were sacrificed and the hearts were excised for histological evaluation.

\section{Ml-induction}

The animals were intubated and mechanically ventilated using a rodent-apparatus (model 7025, Ugo Basile, Comerio, VA, Italy); anesthesia was maintained with a mixture of oxygen and 2.5\% sevoflurane. Through a left thoracotomy, the left coronary artery was encircled and ligated $4 \mathrm{~mm}$ from its origin with a 6-0 suture, extending from the pulmonary cone to the left atrial appendage, as previously (Kolettis et al., 2007); following these anatomical landmarks ensures comparable infarct size (Baltogiannis et al., 2005). The generation of MI was confirmed by the inspection of a pale, akinetic area and by ST elevation in a six-lead ECG (QRS-Card PC-ECG, Pulse Biomedical Inc., PBI, Norristown, PA), after amplification (Cardiology Suite version 4.05, PBI). In sham-operated animals, the left coronary artery was encircled, but not ligated.

\section{Implantation procedure}

The heart was exteriorized and slight traction was applied via a 6-0 suture in the apex, as before (Vilaeti et al., 2013). A total of $0.2 \mathrm{ml}$ of normal-saline or alginate-hydrogel (with or without $\mathrm{GH}$ ) was administered by six intra-myocardial injections in the antero-lateral LV wall, as in earlier experiments (Hatzistergos et al., 2008). The incision was closed in three layers and pneumothorax was evacuated; a single intraperitoneal injection of an opioid-analgesic (buprenorfine, $0.05 \mathrm{mg} / \mathrm{kg}$ ) was given, followed by antibiotic prophylaxis (cephazolin, $15 \mathrm{mg} / \mathrm{kg}$ daily), administered intra-muscularly for 5 days post-operatively.

\section{Echocardiography}

Echocardiography was performed three weeks post-MI, using previously described methodology (Pantos et al., 2008); briefly, under sedation with intra-peritoneal ketamine $(100 \mathrm{mg} / \mathrm{kg})$, short- and long-axis images were acquired using a digital ultrasound-system (Vivid 7, GE Healthcare Bio-Sciences Corp., Piscataway, NJ), equipped with a 14.0MHz-probe. Measurements, averaged from ten consecutive cycles, included LV long- and short-axis diameters at enddiastole and end-systole, as well as posterior-wall thickness at end-diastole. Posterior-wall shortening velocity was measured from M-mode recordings (guided by two-dimensional images), obtained at the mid-LV level.

The analysis was performed by two experienced operators (A. D. V. and P. M.), and was thoroughly reviewed by a third (C. P.), all blinded to group assignment. Ejection fraction (EF) was calculated using the Simpson's principle, whereas the sphericity index was defined as the quotient of short-to-long axis. Wall tension index (WTI), a measure of wall-stress, was defined as LV end-diastolic diameter divided by twice the posterior-wall end-diastolic thickness (Pantos et al., 2008).

\section{Immunohistochemical analysis}

Under sevoflurane-anesthesia, the animals were sacrificed with intra-cardiac $\mathrm{KCl}$ injection, which arrests the heart in diastole; the heart was excised and fixed in 10\% neutralbuffered formalin for histological analysis. The samples (control: $n=5$, alginate: $n=4$, alginate $+\mathrm{GH}: n=4$ ) were embedded in paraffin and were cut axially in $4 \mu \mathrm{m}$-sections; they were rehydrated and stained with hematoxylin/eosin for gross morphological evaluation. The length and thickness of the infarcted area were measured after Heidenhain's AZAN trichrome staining, whereas collagen-content was measured after sirius-red staining.

Additional sections were used for immunohistochemical analysis with the following antibodies: Monoclonal anti$\alpha$-smooth-muscle-actin (Clone 1A4, A2547, Sigma Aldrich) for myofibroblast detection. Monoclonal anti-ED1 antibody for macrophage detection (kindly provided by Professor C. Dijkstra, VU Medical Center, Amsterdam, The Netherlands); the latter staining was enhanced by antigen retrieval (10 min microwave boiling in $1 \mathrm{mM}$ EDTA, at $\mathrm{pH}=8$ ) and avidin/ biotin complex (Vector Laboratories Inc., Burlingame, CA). Blood vessels were stained with Griffonia simplicifolia BSIB4 isolectin (L2140, Sigma Aldrich) and angiogenesis was quantified by counting the total number of vessels in the infarct and peri-infarct areas. Section images were obtained with a camera (DFC490, Leica Microsystems Ltd, Milton Keynes, UK) and were analyzed with QWin 3.1 (Leica). Measurements were obtained from 20 infarct and peri-infarct fields per sample, and were normalized for the total area of the tissue examined. All measurements and analyses were performed by an experienced operator (E. P. D.), blinded to treatment identity.

\section{Statistical analysis}

Values are reported as mean \pm standard error of the mean. Continuous variables were normally distributed, as per the Kolmogorov-Smirnov test; hence, differences between two variables were compared with Student's $t$-test, whereas differences between three or more variables were compared with the analysis of variance, followed by post hoc Duncan's multi-stage test. Statistical significance was defined at an alpha value of 0.05 .

\section{Results}

\section{In vitro alginate-degradation}

The spectra displayed an absorption-band between 240 and $300 \mathrm{~nm}$, peaking at $\sim 250 \mathrm{~nm}$ (Figure 1A), with increasing 

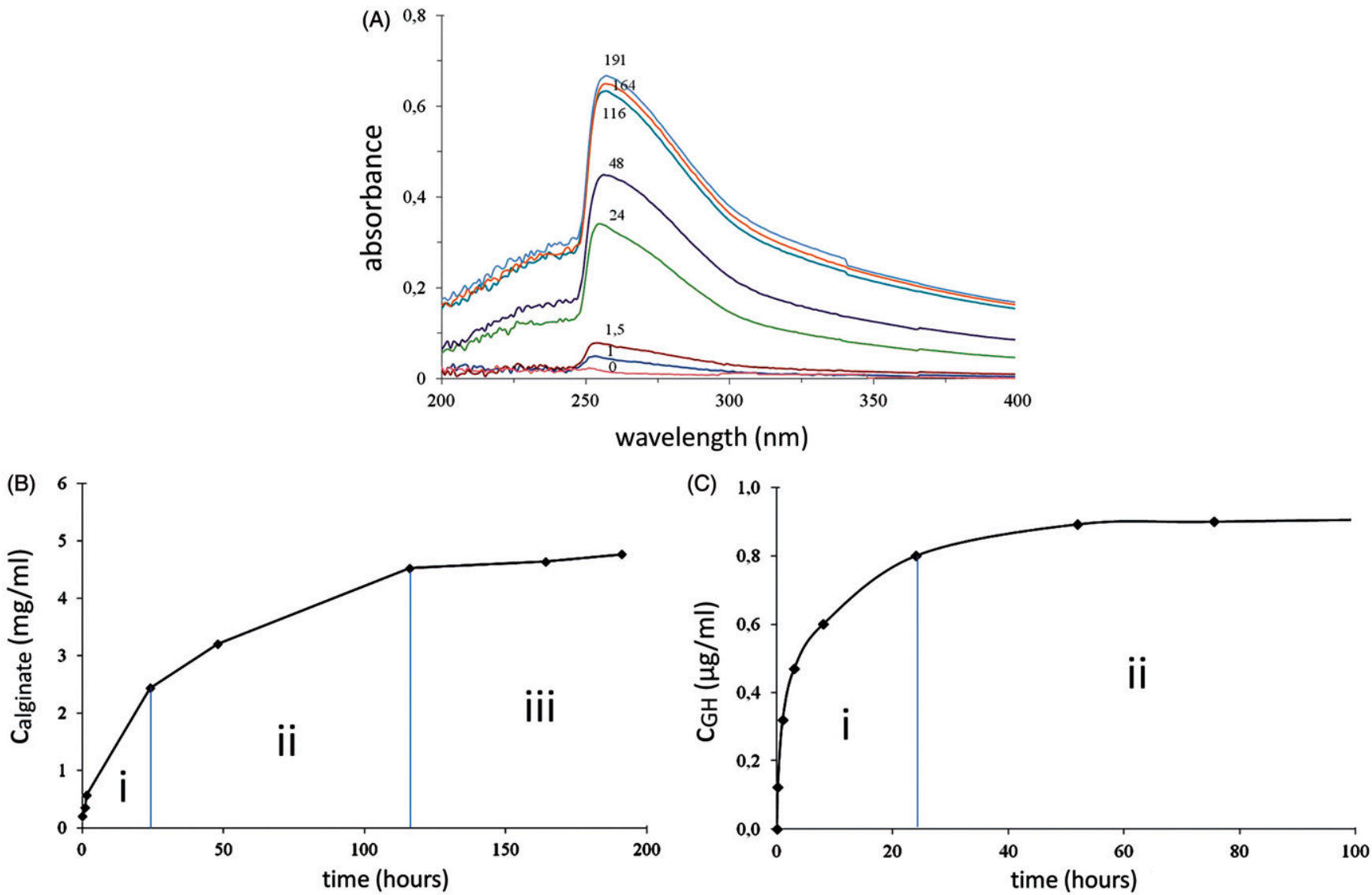

Figure 1. In vitro properties of alginate-hydrogel. Photometric spectra of alginate-hydrogel (A). Degradation (B) displayed an initial steep curve (i), followed by a flattened curve for 4 days (ii) and a plateau for 3 days (iii). GH-release from the alginate-hydrogel (C) occurred mostly during the initial $24 \mathrm{~h}$ (i), followed by a plateau for 3 days (ii).

intensity over time. Alginate-hydrogel displayed an initial steep degradation curve, with $\sim 50 \%$ of the maximal concentration observed at $24 \mathrm{~h}$; this was followed by smooth rates for 4 days and, finally, by a plateau-phase for 3 days. The curve indicates almost complete degradation in vitro at 8 days (Figure 1B).

\section{In vitro GH-release}

As seen in Figure 1C, 70\% of GH was released from the alginate-hydrogel within $24 \mathrm{~h}$; this was followed by a plateau, with completion of GH-release at 3 days.

\section{In vivo alginate-degradation}

The characteristic features of the biotin-alginate spectra were shoulders at 1680 and $1545 \mathrm{~cm}^{-1}$, with a peak at $1267 \mathrm{~cm}^{-1}$. Biotin-alginate (Figure 2) was abundantly present 3 days after injection $(77.8 \pm 4.1 \%$ of the examined area), but only scarcely at 7 days $(2.0 \pm 0.2 \%)$, with nearly complete degradation at 15 days $(0.7 \pm 0.1 \%)$.

\section{Absence of systemic effects after local GH}

Between the beginning and the end of the study, the bodyweight gain after alginate $+\mathrm{GH}$ was $2.3 \pm 0.7 \%$ (of the initial body weight), which was comparable to the $3.4 \pm 1.1 \%$ observed in the remaining animals, not treated with GH.

\section{Echocardiographic indices of LV remodeling and function}

Left ventricular (LV) end-diastolic diameter was shorter in the alginate $+\mathrm{GH}$ group $(5.61 \pm 0.35 \mathrm{~mm})$, when compared to controls $(7.92 \pm 0.34 \mathrm{~mm}, p<0.001)$, or to alginate alone ( $7.21 \pm 0.33 \mathrm{~mm}, p=0.0065)$; interestingly, values were similar to those seen in sham-operated animals $(5.05 \pm 0.32 \mathrm{~mm})$.

End-systolic diameter in the alginate $+\mathrm{GH}$ group $(3.12 \pm 0.21 \mathrm{~mm})$ was comparable to sham-operated animals $(2.55 \pm 0.37 \mathrm{~mm})$, and shorter than in controls $(6.28 \pm 0.48 \mathrm{~mm}, \quad p<0.001), \quad$ or alginate alone $(4.58 \pm 0.38 \mathrm{~mm}, \quad p=0.020)$. Representative examples of M-mode recordings are depicted in Figure 3(A).

The sphericity index (Figure 3B) after alginate $+\mathrm{GH}$ $(0.317 \pm 0.017)$ was almost identical to that observed in sham-operated animals $(0.312 \pm 0.025)$ and improved compared to controls $(0.598 \pm 0.019, p<0.001)$ or alginate alone $(0.406 \pm 0.015, p=0.0043)$.

As expected, EF was lower in the MI-groups (Figure 3C), when compared to sham-operated animals $(69.4 \pm 1.9 \%)$. Between the MI-groups, there was a trend $(p=0.067)$ towards higher $\mathrm{EF}$ in the alginate $+\mathrm{GH}$ group $(50.7 \pm 1.5 \%)$ compared to alginate $(42.1 \pm 2.5 \%)$, although values were comparable to controls $(44.0 \pm 4.3 \%)$. WTI (Figure 3D) was lower after alginate $+\mathrm{GH} \quad(1.436 \pm 0.106), \quad$ compared to controls $(1.951 \pm 0.174, p=0.0083)$ or alginate alone $(2.052 \pm 0.093$, $p=0.0029)$. 
Figure 2. Biotin-labeling of alginate. Examples of microscopic images (scale: $20 \mu \mathrm{m}$ ), 3 (A), 7 (B) and 15 days (C) after biotin-labeled alginate intra-myocardial injection. A control-specimen (salineinjection) is shown in (D).
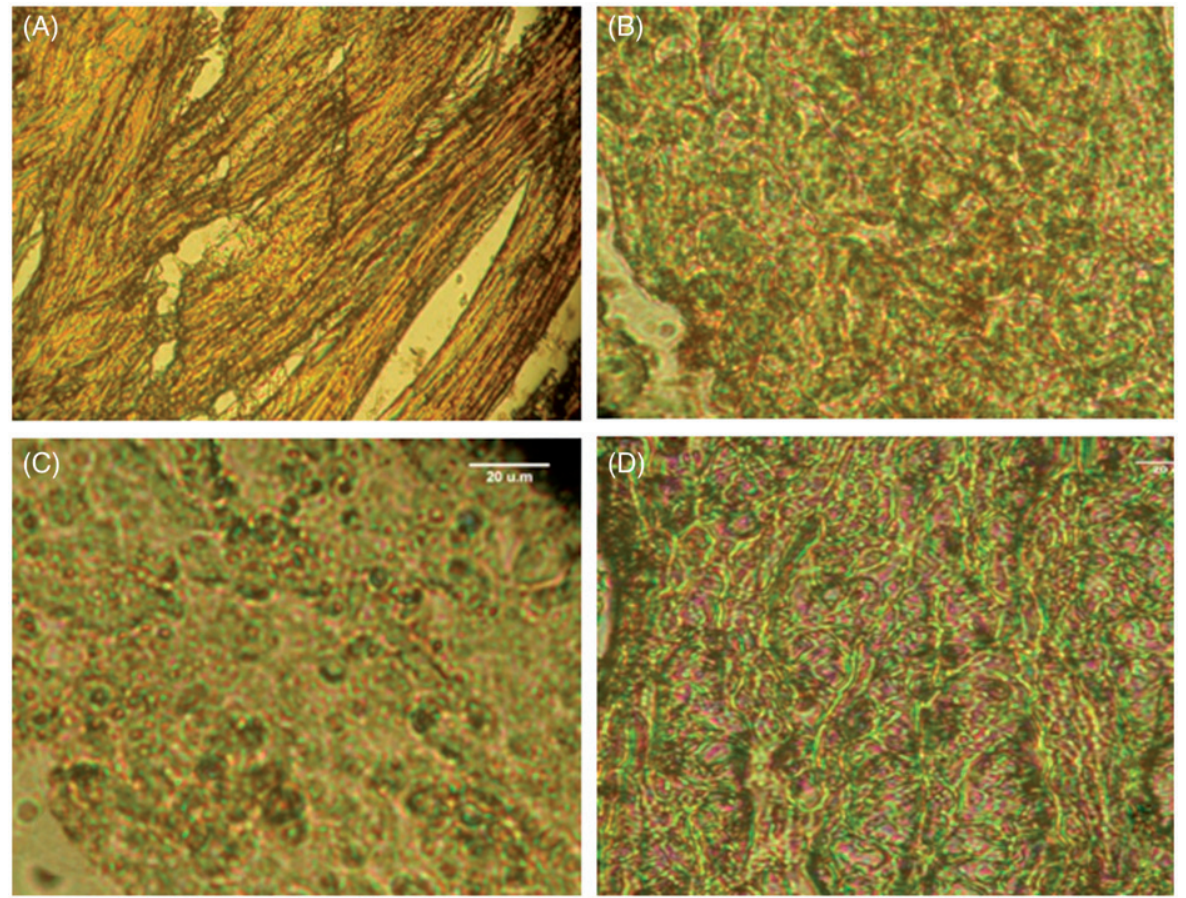
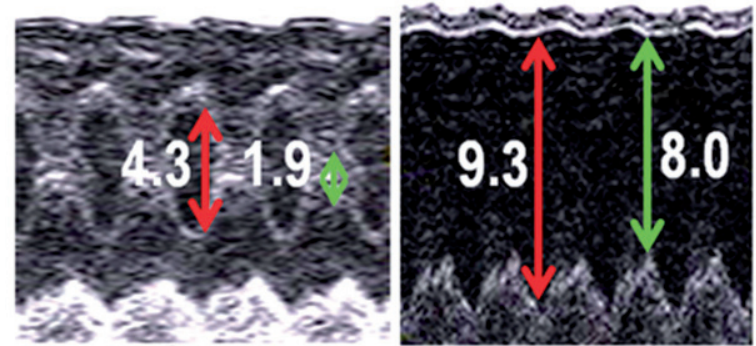

sham

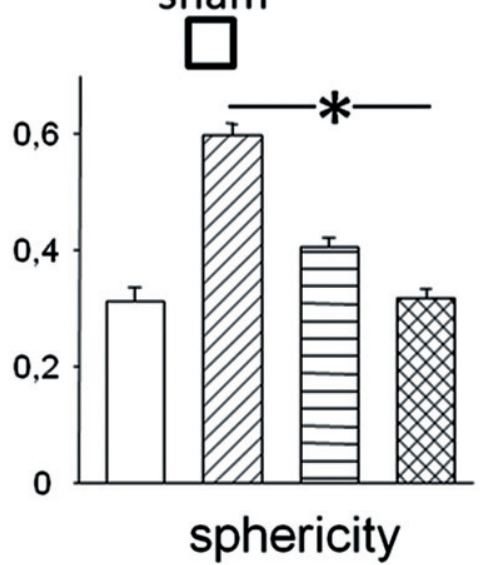

control

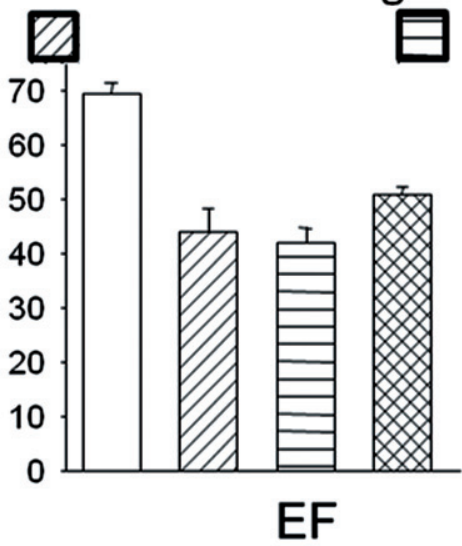

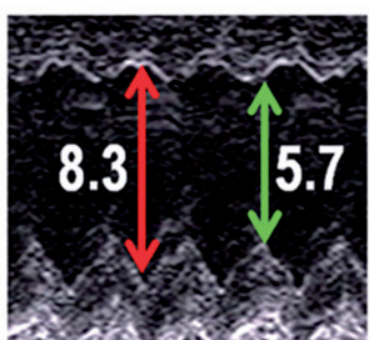

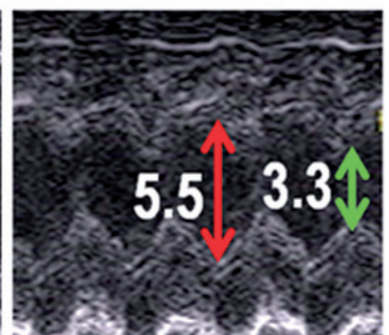

alginate $+\mathrm{GH}$

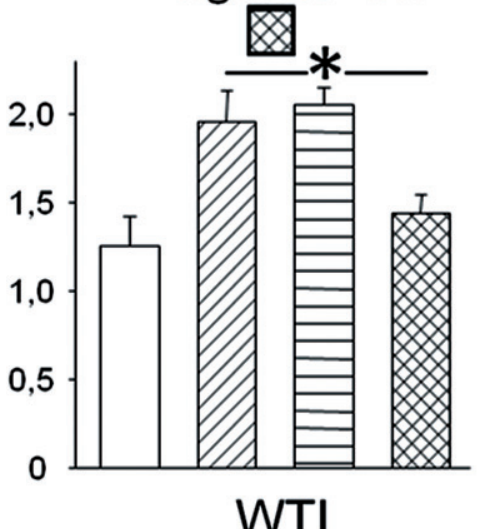

Figure 3. Left ventricular dimensions and shape. Examples from echocardiographic M-mode recordings (upper-panel), showing left ventricular enddiastolic and end-systolic diameters. Sphericity (left-panel), ejection fraction (EF, middle-panel) and wall tension index (WTI, right-panel) in the four groups; note the improved values after alginate + growth hormone $(\mathrm{GH})$. Asterisks denote statistically significant differences.

\section{Histologic indices of LV remodeling}

The collagen-content in the infarct and peri-infarct areas was comparable in the three MI-groups (control: $32.3 \pm 6.9 \%$, alginate: $36.2 \pm 8.7 \%$, alginate $+\mathrm{GH}: 32.6 \pm 6.3 \%)$. Similarly, no significant variance was observed in the length of the infarct-area (as percent of septal-length). In contrast, the thickness of the infarct-area (relative to the non-infarct-zone) was higher after alginate alone $(0.41 \pm 0.04)$ compared to controls $(0.17 \pm 0.02, p=0.013)$. Improved results were seen in the alginate $+\mathrm{GH}$ group $(0.72 \pm 0.06)$, in which infarctthickness was higher compared to controls $(p<0.001)$ or alginate $(p=0.0029)$. Representative examples are shown in Figure 4. 
Figure 4. Infarct-thickness. Examples of the infarct-area thickness after Heidenhain's AZAN-trichrome staining (scale: $500 \mu \mathrm{m}$ ) from slices at the mid-ventricular level, with the right ventricle on the left hand-side. Note the thicker infarct-wall after alginate + growth hormone $(\mathrm{GH})$.
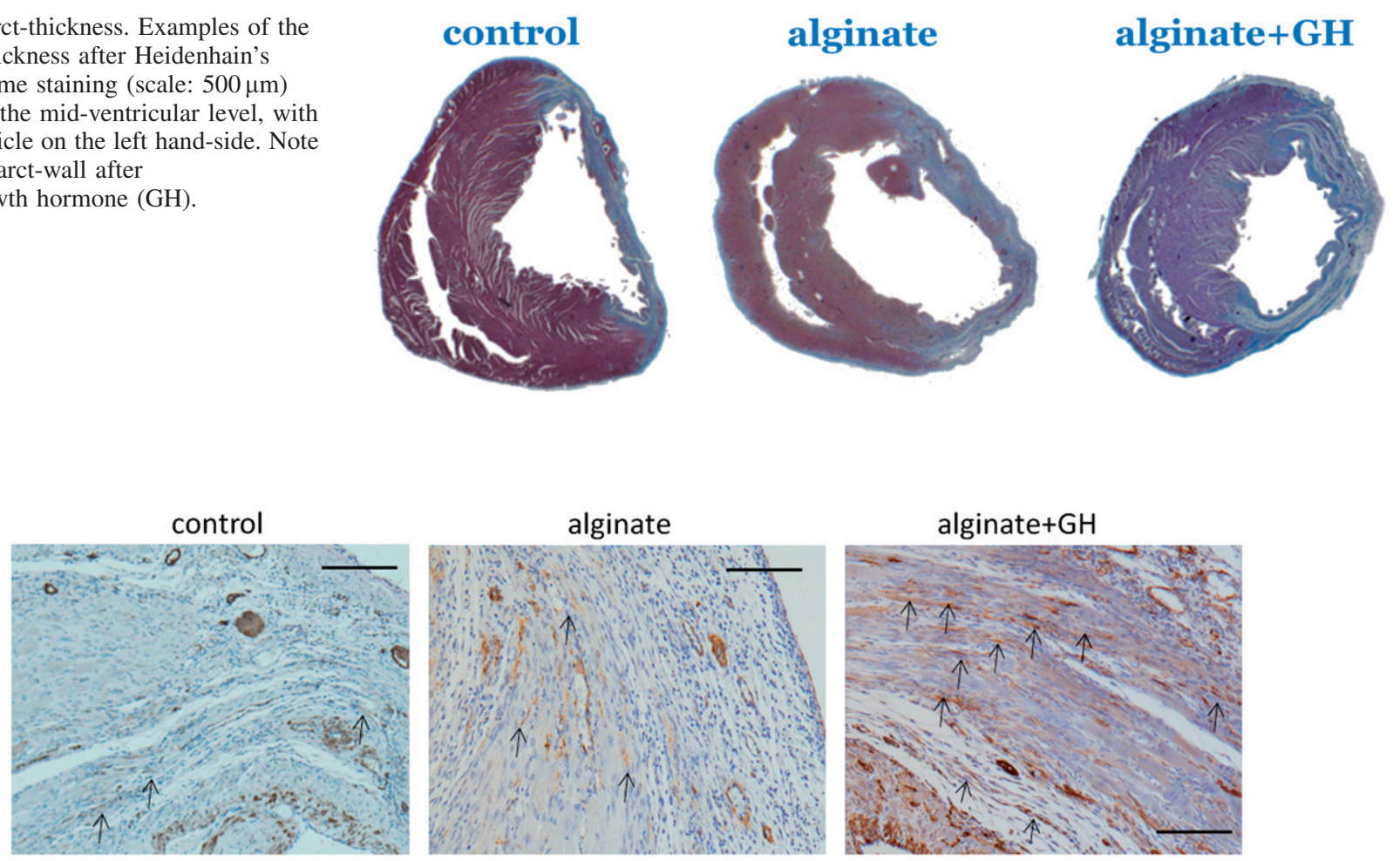

Figure 5. Myofibroblast activation. Examples of $\alpha$-smooth-muscle-actin staining for myofibroblasts (arrows) in the peri-infarct-area (scale: $50 \mu \mathrm{m}$ ); note the higher myofibroblast-density after alginate + growth hormone $(\mathrm{GH})$.

\section{Inflammatory response}

Inflammation was generally of low-intensity in all groups, although slightly more prominent after alginate or alginate $+\mathrm{GH}$ injections; nonetheless, no significant variance was present between groups.

\section{Myofibroblast-count}

Treatment with alginate $+\mathrm{GH}$ was associated with increased presence of myofibroblasts in the infarct-area; specifically, $\alpha$-smooth-muscle-actin positive staining was higher in the alginate $+\mathrm{GH}$ group $(6.25 \pm 1.28 \%)$, compared to controls $(0.77 \pm 0.29 \%, p=0.013)$, albeit only marginally higher $(p=0.069)$ compared to alginate alone $(2.74 \pm 1.22 \%)$. Representative examples of myofibroblast-counts are shown in Figure 5.

\section{Angiogenesis}

Microvascular-density in the infarct-area was higher after alginate $+\mathrm{GH}(6.93 \pm 0.55 \%)$, compared to controls $(3.61 \pm 0.44 \%, p=0.0016)$ or alginate alone $(3.76 \pm 0.44 \%$, $p=0.0018)$. Representative examples are shown in Figure 6.

\section{Discussion}

Chronic heart failure following MI portends an adverse prognosis; therefore, the prevention of LV remodeling constitutes an important therapeutic target (Agathopoulos \& Kolettis, 2014). Growth factors hold a therapeutic potential in this regard (O'Sullivan et al., 2011), calling for further evaluation on their sustained administration. Here, we examined the effects of $\mathrm{GH}$, currently attracting considerable research efforts (Cittadini et al., 1997, 2003, 1996; Elaiopoulos et al., 2007; Jayasankar et al., 2004; Mitsi et al., 2006), administered locally via an alginatehydrogel.

\section{Degradation of alginate-hydrogel and GH-release}

In our in vitro experiments, alginate-hydrogel displayed an initial steep degradation-curve for $24 \mathrm{~h}$, yielding prompt, sustained GH-release during this time-frame. This was deemed necessary, given the early onset of the infarctexpansion process and the previously demonstrated beneficial effects of timely initiation of GH-treatment (Mitsi et al., 2006; O'Sullivan et al., 2011). A second phase, characterized by slower degradation, was observed for a period of 4 days, followed by a 3-day plateau, leading to near-complete degradation at 8 days. These curves, reiterated in our biotinlabeled experiments, ensure biomaterial action during the critical infarct-expansion stage, early post-MI.

\section{Alginate $+\mathrm{GH}$}

Our protocol-design enabled comparison of the alginate $+\mathrm{GH}$ biomaterial-construct not only with controls, but also with alginate alone, given its previously demonstrated beneficial effects on post-MI LV dimensions and shape (Landa et al., 2008). We report additional benefit from local, sustained GHadministration via the alginate-scaffold, supporting our hypothesis on favorable effects of prolonged GH-treatment on LV remodeling (Jayasankar et al., 2004). Body weight was normal after alginate $+\mathrm{GH}$, indicating the absence of systemic effects. Our findings underscore the dual-role of injectable alginate-scaffolds as drug-delivery vehicles and tissue-engineered constructs. 

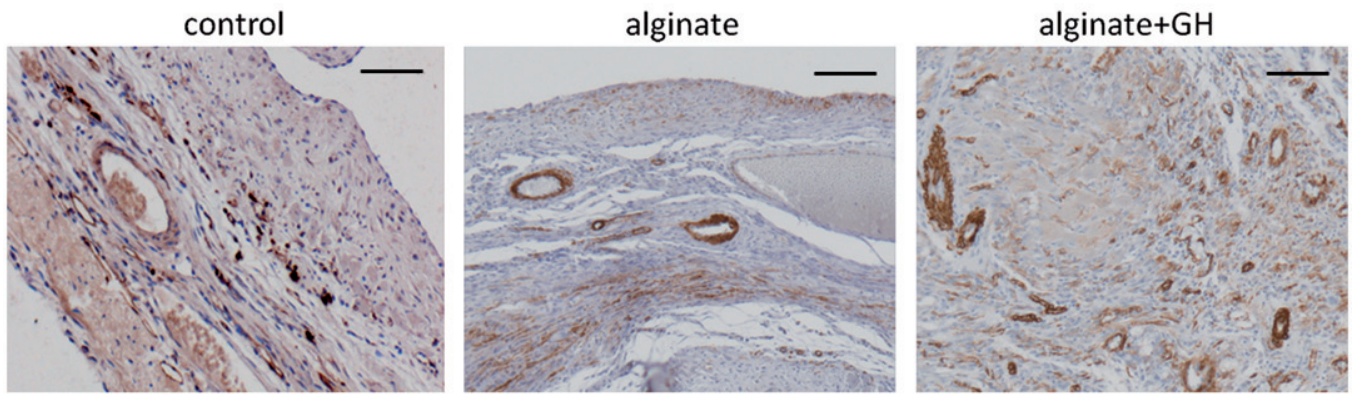

Figure 6. Angiogenesis. Examples of angiogenesis in the peri-infarct-area (scale: $50 \mu \mathrm{m})$; note the higher microvascular-density after alginate + growth hormone $(\mathrm{GH})$.

\section{Infarct thickness and wall-stress}

Infarct thickness was increased after alginate, but it was further improved after alginate $+\mathrm{GH}$, indicating additive effects of both treatment-elements. Our results are in agreement with those reported after sustained release of IGF-1 (followed by hepatocyte growth factor) from an alginatescaffold; intra-myocardial injection of this construct in rats attenuated infarct expansion and preserved scar-thickness, mediated by decreased apoptosis and increased stem-cell recruitment in the peri-infarct area (Ruvinov et al., 2011). Our echocardiographic data expand these observations and indicate that the favorable morphologic changes in the infarct and peri-infarct areas improve global LV architecture, mediated by reduced wall-stress.

According to LaPlace's law, ventricular-wall thinning elevates wall-stress, which constitutes a powerful stimulus for topographic alterations in the infarct and non-infarct zones (Sutton \& Sharpe, 2000); in fact, wall-stress correlates strongly with the development of LV remodeling in patients (Aikawa et al., 2001). The improved WTI, observed 3 weeks after alginate $+\mathrm{GH}$ in our experiments, corroborates the importance of this mechanism on global LV shape and function.

\section{Inflammatory response}

Characterization of the inflammatory/foreign-body response represents an integral part of tissue-engineering research (Anderson et al., 2008); however, there is relative scarcity of relevant data after myocardial alginate-implantation, despite its widespread use. Examined three weeks post-MI, inflammation (in the infarct and peri-infarct areas) was generally mild and similar in the three treatment-groups of our study, although a trend was noted towards more intense response after alginate or alginate $+\mathrm{GH}$ injections. Our experiments do not provide information on earlier time-points, but previous in vitro (Yang \& Jones, 2009) and in vivo (Robitaille et al., 2005) evaluation of alginate suggested prominent early macrophage-activation, with subsequent rapid decline. This inflammation pattern is considered beneficial (Frangogiannis, 2014) and likely contributes to the salutary effects of biomaterial implantation, via the enhancement of inherent healing and regeneration responses (de Jong et al., 2014; Wright et al., 2012).

\section{The role of myofibroblasts}

An interesting observation in our study was the higher myofibroblast-count (in the infarct and peri-infarct areas) following alginate $+\mathrm{GH}$ administration. This finding is in accordance with in vitro studies reporting fibroblast growth and proliferation by GH (Cook et al., 1988; Lee et al., 2010), and provides further explanation for the increased infarctthickness in this group. This statement is reinforced by the previously demonstrated inverse relationship between LV dilatation and myofibroblast-count in the infarct-area (van den Borne et al., 2009). The mechanisms underlying the favorable effects of myofibroblasts are thought to involve changes in cellular proliferation and migration, modulation of extracellular matrix metabolism (Porter \& Turner, 2009) and enhanced angiogenesis by secretion of vascular endothelial growth factor (Chintalgattu et al., 2003), leading to improved healing (Daskalopoulos et al., 2014) and attenuated infarctexpansion (Laeremans et al., 2011).

Of note, the higher myofibroblast-count, observed after alginate $+\mathrm{GH}$, was not accompanied by increased collagencontent. This finding is in agreement with previous reports (Bruel \& Oxlund, 1999; Cittadini et al., 2003; Tanaka et al., 1998), and is beneficial, as excessive fibrosis affects LV relaxation and promotes arrhythmogenesis (Kolettis, 2006). Nonetheless, our present results should be viewed as preliminary, necessitating further research on the effects of $\mathrm{GH}$ on myofibroblast-activation.

\section{Angiogenesis}

The pro-angiogenic actions of GH were demonstrated longago (Struman et al., 1999), and were subsequently confirmed post-MI, after local administration in the porcine-model (Mitsi et al., 2006). The generation of newly formed blood vessels in this setting is important, because better perfusion accelerates infarct-healing processes (Cochain et al., 2013). Thus, in line with previous reports (Banquet et al., 2011; Hao et al., 2007; Ruvinov et al., 2011), the enhanced angiogenesis (observed after alginate $+\mathrm{GH}$ in our experiments) presents as an additional mechanism for improved morphology of the infarct-area.

\section{Strengths and limitations of the study}

We evaluated the sustained GH-release via a biomaterialscaffold, which resulted in additive effects of both elements. This approach was implemented immediately post-MI, favoring the emerging concept targeting the prevention of topographic LV alterations, as opposed to their reversal in established heart failure; in the clinical setting, such treatments may be combined with revascularization procedures, 
should this approach surface into clinical trials. The inclusion of in vivo functional data in our experiments, along with morphological end-points, adds value to the study; in addition, we included only male rats in our experiments, thereby avoiding gender as a possible confounding factor. Finally, we focused on the intriguing effects of $\mathrm{GH}$ on angiogenesis and myofibroblast-activation. Despite these strengths, four limitations should be noted. First, due to the relatively small number of observations, the treatment-effects on mortality were not examined. Second, despite the reproducibility of infarct size elicited by the ligation procedure, additional echocardiographic studies (performed early postligation) would have strengthened our results. Third, the inclusion of a rat group treated with $\mathrm{GH}$ alone would have enabled more comprehensive assessment of anti-remodeling strategies. Finally, the 3-week time-frame post-ligation suffices for the evaluation of LV remodeling, but longer intervals would have permitted the assessment of its progression into chronic heart failure.

\section{Conclusions}

Local GH-administration via an alginate-scaffold attenuated LV remodeling and improved LV function in the rat MImodel, more effectively than alginate alone. These actions, secondary to preserved scar-thickness and reduced wallstress, can be attributed to the beneficial actions of $\mathrm{GH}$ on infarct healing, mediated by enhanced angiogenesis and myofibroblast-activation. Local, sustained GH-administration constitutes a promising strategy for the prevention of post-MI LV remodeling. Further work is needed on the optimal duration of GH-treatment, including comparison between single-dose, versus short- and long-term sustained administration, the latter encompassing the entire remodeling period.

\section{Acknowledgements}

The skillful technical assistance of Lily Vervoort-Peters (Department of Pharmacology, Cardiovascular Research Institute Maastricht, Maastricht University, The Netherlands) in the immunohistochemistry experiments is gratefully acknowledged. We thank Prof H. Stamatis and Dr M. Katsoura (Department of Biological Applications and Technology, University of Ioannina, Greece) for their help in fluorescence measurements. We also thank Eleftheria Karampela, Nikolaos Psychalakis, Kalliopi Tsarea, Maria Karamperi and Antonios Karaiskos (Experimental Research Center ELPEN, Pikermi, Athens, Greece) and Anastasia Fambri (medical student at the University of Ioannina) for their valuable help during the experiments. The animal care provided by Stergios Gerakis and Evripidis Gerakis (Experimental Research Center ELPEN, Pikermi, Athens, Greece) is gratefully acknowledged. Eleni Goga (Cardiovascular Research Institute, Ioannina and Athens, Greece) efficiently coordinated this research.

\section{Declaration of interest}

The authors report no declarations of interest.

\section{References}

Agathopoulos S, Kolettis TM. 2014. Editorial: Novel strategies for cardiac repair post-myocardial infarction. Curr Pharm Des 20: 1925-1929.

Aikawa Y, Rohde L, Plehn J, Greaves SC, Menapace F, Arnold MO, Rouleau JL, et al. 2001. Regional wall stress predicts ventricular remodeling after anteroseptal myocardial infarction in the Healing and Early Afterload Reducing Trial (HEART): An echocardiographybased structural analysis. Am Heart J 141:234-242.

Anderson JM, Rodriguez A, Chang DT. 2008. Foreign body reaction to biomaterials. Semin Immunol 20:86-100.

Augst AD, Kong HJ, Mooney DJ. 2006. Alginate hydrogels as biomaterials. Macromol Biosci 6:623-633.

Baltogiannis GG, Tsalikakis DG, Mitsi AC, Hatzistergos KE, Elaiopoulos D, Fotiadis DI, Kyriakides ZS, Kolettis TM. 2005. Endothelin receptor-A blockade decreases ventricular arrhythmias after myocardial infarction in rats. Cardiovasc Res 67:647-654.

Banquet S, Gomez E, Nicol L, Edwards-Levy F, Henry JP, Cao R, Schapman D, et al. 2011. Arteriogenic therapy by intramyocardial sustained delivery of a novel growth factor combination prevents chronic heart failure. Circulation 124:1059-1069.

Bruel A, Oxlund H. 1999. The effect of growth hormone on rat myocardial collagen. Growth Horm IGF Res 9:123-130.

Chintalgattu V, Nair DM, Katwa LC. 2003. Cardiac myofibroblasts: A novel source of vascular endothelial growth factor (VEGF) and its receptors Flt-1 and KDR. J Mol Cell Cardiol 35:277-286.

Cittadini A, Grossman JD, Napoli R, Katz SE, Stromer H, Smith RJ, Clark R, et al. 1997. Growth hormone attenuates early left ventricular remodeling and improves cardiac function in rats with large myocardial infarction. J Am Coll Cardiol 29:1109-1116.

Cittadini A, Isgaard J, Monti MG, Casaburi C, Di Gianni A, Serpico R, Iaccarino G, Sacca L. 2003. Growth hormone prolongs survival in experimental postinfarction heart failure. J Am Coll Cardiol 41: 2154-2163.

Cittadini A, Strömer H, Katz SE, Clark R, Moses AC, Morgan JP, Douglas PS. 1996. Differential cardiac effects of growth hormone and insulin-like growth factor-1 in the rat. A combined in vivo and in vitro evaluation. Circulation 93:800-809.

Cochain C, Channon KM, Silvestre JS. 2013. Angiogenesis in the infarcted myocardium. Antioxid Redox Signal 18:1100-1113.

Cook JJ, Haynes KM, Werther GA. 1988. Mitogenic effects of growth hormone in cultured human fibroblasts. Evidence for action via local insulin-like growth factor I production. J Clin Invest 81:206-212.

Daskalopoulos EP, Hermans KC, Blankesteijn WM. 2014. Cardiac (myo)fibroblast: Novel strategies for its targeting following myocardial infarction. Curr Pharm Des 20:1987-2002.

de Jong R, van Hout GP, Houtgraaf JH, Kazemi K, Wallrapp C, Lewis A, Pasterkamp G, et al. 2014. Intracoronary infusion of encapsulated glucagon-like peptide-1-eluting mesenchymal stem cells preserves left ventricular function in a porcine model of acute myocardial infarction. Circ Cardiovasc Interv 7:673-683.

Elaiopoulos DA, Tsalikakis DG, Agelaki MG, Baltogiannis GG, Mitsi AC, Fotiadis DI, Kolettis TM. 2007. Growth hormone decreases phase II ventricular tachyarrhythmias during acute myocardial infarction in rats. Clin Sci (Lond) 112:385-391.

Ertl G, Frantz S. 2005. Healing after myocardial infarction. Cardiovasc Res 66:22-32.

Frangogiannis NG. 2014. The inflammatory response in myocardial injury, repair, and remodelling. Nat Rev Cardiol 11:255-265.

Friberg L, Werner S, Eggertsen G, Ahnve S. 2000. Growth hormone and insulin-like growth factor-1 in acute myocardial infarction. Eur Heart J 21:1547-1554.

Hao X, Silva EA, Mansson-Broberg A, Grinnemo KH, Siddiqui AJ, Dellgren G, Wardell E, et al. 2007. Angiogenic effects of sequential release of VEGF-A165 and PDGF-BB with alginate hydrogels after myocardial infarction. Cardiovasc Res 75:178-185.

Hatzistergos KE, Mitsi AC, Zachariou C, Skyrlas A, Kapatou E, Agelaki MG, Fotopoulos A, et al. 2008. Randomised comparison of growth hormone versus IGF-1 on early post-myocardial infarction ventricular remodelling in rats. Growth Horm IGF Res 18:157-165.

Jayasankar V, Pirolli TJ, Bish LT, Berry MF, Burdick J, Grand T, Woo YJ. 2004. Targeted overexpression of growth hormone by adenoviral gene transfer preserves myocardial function and ventricular geometry in ischemic cardiomyopathy. J Mol Cell Cardiol 36:531-538. 
Jin H, Yang R, Lu H, Ogasawara AK, Li W, Ryan A, Peale F, Paoni NF. 2002. Effects of early treatment with growth hormone on infarct size, survival, and cardiac gene expression after acute myocardial infarction. Growth Horm IGF Res 12:208-215.

Khan AS, Lynch CD, Sane DC, Willingham MC, Sonntag WE. 2001. Growth hormone increases regional coronary blood flow and capillary density in aged rats. J Gerontol A Biol Sci Med Sci 56:B364-B371.

Kolettis TM. 2006. Arrhythmogenesis after cell transplantation postmyocardial infarction. Four burning questions-and some answers. Cardiovasc Res 69:299-301.

Kolettis TM, Agelaki MG, Baltogiannis GG, Vlahos AP, Mourouzis I, Fotopoulos A, Pantos C. 2007. Comparative effects of acute vs. chronic oral amiodarone treatment during acute myocardial infarction in rats. Europace 9:1099-1104.

Kolettis TM, Vilaeti A, Dimos K, Tsitou N, Agathopoulos S. 2011. Tissue engineering for post-myocardial infarction ventricular remodeling. Mini Rev Med Chem 11:263-270.

Kontonika M, Barka E, Daskalopoulos EP, Vilaeti AD, Papalois A, Agathopoulos S, Kolettis TM. 2014. Effects of myocardial alginate injections on ventricular arrhythmias after experimental ischemiareperfusion. Trends Biomater Artif Organs 28:79-82.

Laeremans H, Hackeng TM, van Zandvoort MA, Thijssen VL, Janssen BJ, Ottenheijm HC, Smits JF, Blankesteijn WM. 2011. Blocking of frizzled signaling with a homologous peptide fragment of wnt3a/ wnt5a reduces infarct expansion and prevents the development of heart failure after myocardial infarction. Circulation 124:1626-1635.

Landa N, Miller L, Feinberg MS, Holbova R, Shachar M, Freeman I, Cohen S, Leor J. 2008. Effect of injectable alginate implant on cardiac remodeling and function after recent and old infarcts in rat. Circulation 117:1388-1396.

Lee SW, Kim SH, Kim JY, Lee Y. 2010. The effect of growth hormone on fibroblast proliferation and keratinocyte migration. J Plast Reconstr Aesthet Surg 63:e364-e369.

Mitsi AC, Hatzistergos K, Baltogiannis GG, Kolettis TM. 2005. Early, selective growth hormone administration may ameliorate left ventricular remodeling after myocardial infarction. Med Hypotheses 64: $582-585$

Mitsi AC, Hatzistergos KE, Niokou D, Pappa L, Baltogiannis GG, Tsalikakis DG, Papalois A, et al. 2006. Early, intracoronary growth hormone administration attenuates ventricular remodeling in a porcine model of myocardial infarction. Growth Horm IGF Res 16:93-100.

Mukherjee R, Zavadzkas JA, Saunders SM, McLean JE, Jeffords LB, Beck C, Stroud RE, et al. 2008. Targeted myocardial microinjections of a biocomposite material reduces infarct expansion in pigs. Ann Thorac Surg 86:1268-1276.

Nagasawa N, Mitomo H, Yoshii F, Kume T. 2000. Radiation-induced degradation of sodium alginate. Polym Degrad Stabil 69:279-285.
O’Sullivan JF, Leblond AL, Kelly G, Kumar AH, Metharom P, Buneker CK, Alizadeh-Vikali N, et al. 2011. Potent long-term cardioprotective effects of single low-dose insulin-like growth factor-1 treatment postmyocardial infarction. Circ Cardiovasc Interv 4:327-335.

Omerovic E, Bollano E, Mobini R, Kujacic V, Madhu B, Soussi B, Fu M, et al. 2000. Growth hormone improves bioenergetics and decreases catecholamines in postinfarct rat hearts. Endocrinology 141: $4592-4599$.

Pantos C, Mourouzis I, Markakis K, Tsagoulis N, Panagiotou M, Cokkinos DV. 2008. Long-term thyroid hormone administration reshapes left ventricular chamber and improves cardiac function after myocardial infarction in rats. Basic Res Cardiol 103:308-318.

Porter KE, Turner NA. 2009. Cardiac fibroblasts: At the heart of myocardial remodeling. Pharmacol Ther 123:255-278.

Robitaille R, Dusseault J, Henley N, Desbiens K, Labrecque N, Halle JP. 2005. Inflammatory response to peritoneal implantation of alginatepoly-L-lysine microcapsules. Biomaterials 26:4119-4127.

Rowley JA, Madlambayan G, Mooney DJ. 1999. Alginate hydrogels as synthetic extracellular matrix materials. Biomaterials 20:45-53.

Ruvinov E, Leor J, Cohen S. 2011. The promotion of myocardial repair by the sequential delivery of IGF-1 and HGF from an injectable alginate biomaterial in a model of acute myocardial infarction. Biomaterials 32:565-578.

Struman I, Bentzien F, Lee H, Mainfroid V, D’Angelo G, Goffin V, Weiner RI, Martial JA. 1999. Opposing actions of intact and $\mathrm{N}$-terminal fragments of the human prolactin/growth hormone family members on angiogenesis: An efficient mechanism for the regulation of angiogenesis. Proc Natl Acad Sci USA 96:1246-1251.

Sutton MG, Sharpe N. 2000. Left ventricular remodeling after myocardial infarction: Pathophysiology and therapy. Circulation 101: 2981-2988.

Tanaka N, Ryoke T, Hongo M, Mao L, Rockman HA, Clark RG, Ross Jr J. 1998. Effects of growth hormone and IGF-I on cardiac hypertrophy and gene expression in mice. Am J Physiol 275:H393-H399.

van den Borne SW, van de Schans VA, Strzelecka AE, Vervoort-Peters HT, Lijnen PM, Cleutjens JP, Smits JF, et al. 2009. Mouse strain determines the outcome of wound healing after myocardial infarction. Cardiovasc Res 84:273-282.

Vilaeti AD, Dimos K, Lampri ES, Mantzouratou P, Tsitou N, Mourouzis I, Oikonomidis DL, et al. 2013. Short-term ventricular restraint attenuates post-infarction remodeling in rats. Int $\mathrm{J}$ Cardiol 165: 278-284.

Wright EJ, Farrell KA, Malik N, Kassem M, Lewis AL, Wallrapp C, Holt CM. 2012. Encapsulated glucagon-like peptide-1-producing mesenchymal stem cells have a beneficial effect on failing pig hearts. Stem Cells Transl Med 1:759-769.

Yang D, Jones KS. 2009. Effect of alginate on innate immune activation of macrophages. J Biomed Mater Res A 90:411-418. 